


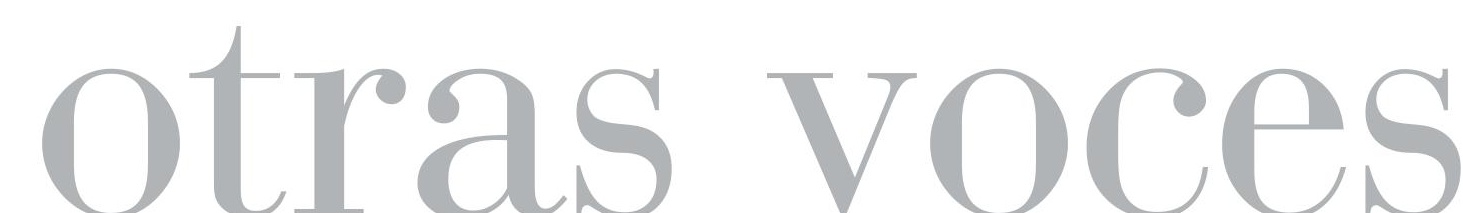





\section{"Eso no es lo mio": un análisis de conflictos en la apropiación de prácticas de literacidad académica ${ }^{1}$}

\footnotetext{
Luanda Sito ${ }^{2}$

Universidad de Antioquia (UdeA), Medellín, Colombia

luandasito@gmail.com

Angela Kleiman ${ }^{3}$

Universidade Estadual de Campinas (UNICAMP), Campinas, Brasil akleiman@mpc.com.br

Recibido: 21 de enero de 2016

Aceptado: 31 de mayo de 2016

Disponible en línea: 20 de diciembre de 2016

1 Artículo de investigación; presenta resultados de una tesis doctoral titulada Escritas afirmativas: estratégias criativas para subverter a colonialidade em trajetórias de letramento acadêmico, desarrollada en el Instituto de Estudos da Linguagem de la Universidade Estadual de Campinas (UNICAMP), y financiada por la Fundação de Amparo à Pesquisa do Estado de São Paulo (FAPESP). Agradecemos a FAPESP el apoyo para la realización de ese estudio.

2 Doctora en Lingüística Aplicada, UNICAMP (Brasil). Docente, Facultad de Educación de la Universidad de Antioquia (Medellín, Colombia).

3 Doctora en Lingüística, Universidad de Illinois (Estados Unidos). Profesora Titular y colaboradora del Instituto de Estudos da Linguagem, UNICAMP (Campinas, Brasil).
} 


\title{
"Eso no es lo mio": un análisis de conflictos en la apropiación de prácticas de literacidad académica
}

\section{Resumen}

En este artículo examinamos conflictos que emergieron durante la apropiación de prácticas de literacidad académica, por parte de universitarios afros e indígenas que ingresaron a universidades públicas a través de acciones afirmativas en Brasil y Colombia. Analizamos parte de un corpus generado para una investigación doctoral, cuyo objeto fue la literacidad académica. En ese estudio, de carácter cualitativo, utilizamos entrevistas a estudiantes y documentos oficiales de la política afirmativa. Desde el marco de la Lingüística aplicada, nuestra investigación se fundamenta en los Estudios de Literacidad y en la teoría del círculo de Bajtín. Los conflictos en las trayectorias de literacidad académica de esos estudiantes, además de denotar (des) encuentros con la universidad, interpelan las politicas interculturales desde sus experiencias, revelando aspectos de la vida universitaria que no suelen ser contemplados en las discusiones de permanencia de los programas de acción afirmativa, como la interculturalidad y el lenguaje. Palabras clave: literacidad académica; acciones afirmativas; apropiación

\section{"This Isn't My Thing": A Conflict Analysis in the Appropriation of Academic Literacy Practices}

\begin{abstract}
In this paper, we examine conflicts experienced by Brazilian and Colombian black and indigenous university students during the process of appropriation of academic literacy practices, after they were admitted to public universities through affirmative action programs in their countries. We analyze part of a doctoral research corpus concerning academic literacy. This qualitative study student uses interviews and official affirmative policy documents. From an Applied Linguistics perspective, our research draws on Bakhtin's concept of dialogism and Street's work on academic literacies. Conflicts that arise in the student's path towards academic literacy not only show the (dis)agreements with the university, but also question intercultural policies from their own experience. This whole process reveals aspects of university life that remain unexamined, even in affirmative action discussions, such as interculturality and language.
\end{abstract}

Keywords: academic literacies; affirmative action programs; appropriation

\section{"Eu não dou para isso": análise dos conflitos na apropriação de práticas de literacia acadêmica}

\section{Resumo}

Neste artigo examinamos os conflitos que surgiram durante a apropriação de práticas de literacia acadêmica por universitários afros e indígenas admitidos nas universidades públicas, através de ação afirmativa no Brasil e na Colômbia. Analisamos parte de um corpus gerado para pesquisa de doutorado, cujo objeto era a literacia acadêmica. Nesse estudo, de caráter qualitativo, usamos entrevistas com alunos e documentos oficiais de politica afirmativa. A partir do quadro da Linguística Aplicada, nossa pesquisa é baseada em Estudos de literacia e na teoria de Círculo de Bakhtin. Os conflitos nas trajetórias de literacia acadêmica desses estudantes, além de denotar (des)encontros com a universidade, questionam as politicas interculturais a partir das suas experiências, revelando aspectos da vida universitária que normalmente não são cobertas nas discussões sobre a permanência dos programas de ação afirmativa, como a interculturalidade e a linguagem.

Palabras-chave: literacia acadêmica; ações afirmativas; apropriação 


\section{Introducción}

En América Latina, el siglo XXI inició con la demanda e implementación de acciones afirmativas ${ }^{4}$ en la educación superior, para que la universidad abriera sus puertas a los estudiantes de los grupos que habian sido marginados física y culturalmente del espacio académico, a lo largo de la historia. Esta entrada generó controversias: mientras que, para algunos sectores de la universidad, los estudiantes que ingresaban por la acción afirmativa no serian capaces de hacer frente a las exigencias académicas - una mirada del déficit-, para otros, estos no solo tendrían éxito en su formación, sino que serian capaces de romper con los discursos hegemónicos y de proponer nuevas formas de producción de conocimiento - una mirada desde la interculturalidad-.

En diálogo con ese contexto de fondo -el proceso de implementación de políticas afirmativas-, en este artículo analizaremos parte del corpus generado para una investigación doctoral, cuyo objeto fue analizar trayectoria ${ }^{5}$ de literacidad académica, enfocándose en la producción de la tesis de grado. Vinculada al grupo de investigación Letramento do Professor ${ }^{6}$ la investigación consistió en un estudio de carácter cualitativo, del cual presentamos, en este artículo, análisis de entrevistas a estudiantes.

Nuestro enfoque se centrará en los conflictos que emergieron en la apropiación de prácticas de literacidad académica por parte de los estudiantes participantes. Tomando la universidad como una zona de contacto (Pratt, 1991; Canagarajah, 1997), nos alineamos con la perspectiva de los nuevos estudios de literacidad (Heath, 1982; Street, 1993; Kleiman, 1995; Zavala, Niño-Murcia y Ames, 2004) en el campo de la Lingüística aplicada. Con esa discusión, pretendemos aportar a los debates sobre interculturalidad y politicas afirmativas para las

4 En este trabajo esas políticas serán también llamadas política(s) afirmativa(s), medidas de acción afirmativa o acciones afirmativas.

5 La palabra 'trayectorias' será utilizada en su sentido común, como "curso que, a lo largo del tiempo, sigue el comportamiento o el ser de una persona" (cfr. RAE).

6 El Núcleo de Investigación Letramento do Professor fue creado en 1991, con el fin de aglutinar grupos de investigadores que estudian las prácticas de lectura y escritura de alfabetizadores, profesores de lengua portuguesa y otros agentes de literacidad. Más información disponible en: http://www.letramento.iel.unicamp.br/portal 
víctimas de racismo, desde los estudios sobre literacidades académicas y formación docente.

Nuestra discusión está organizada en tres momentos: empezamos por una revisión de aspectos que entrelazan experiencias de politica afirmativa de Brasil y Colombia; luego, presentamos nuestro marco teórico-metodológico, con conceptos claves del campo y los presupuestos del abordaje cualitativo-interpretativista adoptado; enseguida, analizamos los conflictos con la literacidad académica, y concluimos con las consideraciones finales.

\section{Entrelazamientos entre Brasil y Colombia}

Las conexiones entre Brasil y Colombia van más allá de sus fronteras en la región amazónica. Los trabajos de Arruti (2000) y Rodrigues (2012) ya apuntan acerca de las similitudes en las politicas afirmativas para poblaciones afrodescendientes en el sector territorial, como los casos de tierras quilombolas y de territorios étnicos. En ese escenario, destacamos otros cuatro aspectos que entrelazan a ambos países.

El primer aspecto es la ideología de la democracia racial, la cual sostiene un juego de doble realidad: por un lado, un panorama de desigualdad que persiste sistemáticamente y, por otro, en paralelo, la valoración de un discurso que niega la existencia de procesos de racialización y racismo, que son enfrentados cotidianamente por sus poblaciones afrodescendientes e indigenas (Wade, 1997; Munanga, 1999), y resultan en desigualdades. El segundo aspecto radica en la reelaboración de sus cartas magnas entre el final de 1980 e inicio de 1990 -la Constituição Federal do Brasil, de 1988, y la Constitución Politica de Colombia, de 1991-, las cuales lograron garantizar más derechos humanos, al reconocer la diversidad étnica y cultural de sus países. El tercer aspecto fue el refrendo, por parte de ambos Estados, del Plan de Acción de la III Conferencia de Durban (ONU, 2001). Al hacerlo, Brasil y Colombia reconocieron las demandas y denuncias de diversas organizaciones del movimiento social frente a la desigualdad etnorracial de 
sus países. El cuarto y último aspecto es la expansión de la educación superior y de reivindicaciones por equidad (Soler, 2013; Carvalho, 2004; Sierra, 2004). Las universidades diversificaron su público; tanto externamente, con programas de internacionalización, como internamente, con la creación de programas -en especial, licenciaturas- interculturales, y la reserva de cupos o cupos adicionales.

Si detallamos el último aspecto, vemos también una cercanía entre las politicas implementadas por universidades de Brasil y Colombia, que involucraron el tema étnico y racial en sus procesos selectivos como forma de disminuir la desigualdad histórica de sus pueblos. Las categorias de 'minorias étnicas', en Colombia, y de 'etnorracial', en Brasil, contemplan a las poblaciones afrodescendientes -en Brasil, también llamadas negras ${ }^{7}-$ e indígenas. Esa selección está acorde con el propósito de las acciones afirmativas, que son, según Carvalho (2004, p. 51, traducción nuestra):

corregir una historia de desigualdades y desventajas sufridas por un grupo racial (o étnico), en general frente a un Estado nacional que lo discriminó negativamente. Lo que motiva esas políticas es la conciencia de que esas desigualdades suelen perpetuarse si el Estado continúa utilizando los mismos principios universalistas, con los cuales viene funcionado hasta ahora, en la distribución de recursos y oportunidades para las poblaciones que cuentan con una historia de siglos de discriminación.

Así, al proponer políticas afirmativas, se reconoce que hay algunas identidades que son vistas como diferentes, y que esas diferencias promueven experiencias sistemáticas de discriminación que resultan en desigualdad. Esta correlación entre identidad-diferencias-desigualdad es la base para la creación de acciones que reviertan esas desigualdades históricas, con el fin de construir una sociedad con justicia.

\footnotetext{
En la década de los noventa, organizaciones del movimiento social negro realizaron una serie de campañas para resignificar la palabra 'negro', con el fin de subvertir sus sentidos de opresión en un término positivo. Preto es la palabra usada para referirse al color negro de los objetos y, de modo despectivo, a las personas negras. Entre los slogans estaban: "Preto é cor, negro é raça!" y "Negro é lindo".
} 
En escenarios tan desiguales, en los cuales persisten las consecuencias del proyecto colonial (Quijano, 2000), entendemos que la justicia necesita ser construida. Por eso, nos parece importante analizar cómo los sujetos están construyendo las políticas en su cotidiano, para entender cómo los estudiantes que ingresaron por acciones afirmativas interpelan esas políticas interculturales desde sus propias experiencias.

\section{Las politicas de las instituciones gaucha y paisa}

La investigación abordó la política afirmativa de dos instituciones de educación superior públicas, ubicadas en los departamentos de Antioquia, en Colombia, y Rio Grande del Sur, en Brasil. Esas regiones -región andina colombiana y sureña brasileña (Wade, 1997; Oliven, 1999) - fomentaron discursos que las distanciaban de las identidades nacionales tropicales a partir de un distintivo: la blancura (Viveros, 2013). Debido a eso, nuestra motivación fue entender cómo, en un contexto regional donde el imaginario local es sesgado por el blanqueamiento, estudiantes marcados por el estigma racial (Goffman, 1988) aprendían a participar de ese nuevo espacio, lo que implica dominar sus formas de hacer y decir; así como averiguar si construían estrategias para mantener lazos con sus comunidades de origen.

Las políticas afirmativas de las dos instituciones investigadas son orientadas a jóvenes que provienen de comunidades afrodescendientes e indígenas. Sin embargo, debido a sus sistemas de acceso -exámenes de admisión- son políticas con enfoque en individuos y no en sus comunidades. Los estudiantes certifican sus identidades etnorraciales con un aval, en el caso colombiano e indígena brasileño, o con una autodeclaración, en el caso de estudiantes negros brasileños.

En la institución gaucha el primer diseño del programa de acción afirmativa destinaba 10 cupos adicionales al año para estudiantes indígenas, en programas elegidos junto a representantes de comunidades indigenas, y reservaba $30 \%$ de los cupos totales ofrecidos en el examen de admisión por semestre, para estudiantes de escuela 
pública; de estos, la mitad era para los estudiantes autodeclarados negros. En la institución paisa se ofertaban cuatro cupos por cada programa a estudiantes de comunidades afrodescendientes e indígenas. En todos los casos, era realizado un examen selectivo para la admisión de los estudiantes.

\section{Estudios de literacidad y la esfera académica}

En nuestra experiencia en la universidad - sea como docentes o estudiantes-, vivimos un escenario de intenso debate en torno a las acciones afirmativas en Brasil, en especial después de la III Conferencia Mundial contra el Racismo, la Discriminación Racial, la Xenofobia y las Formas Conexas de Intolerancia, en 2001 (Carvalho, 2004; Moreira e Pereira, 2011; Sito, 2014). Luego, al observar experiencias de acción afirmativa en otros países de Latinoamérica, constatamos, primero, una cercanía entre Brasil y Colombia en el perfil de las medidas afirmativas para la educación superior, y segundo, una presión vivida por los universitarios que accedieron por esas acciones - presiones relacionadas, especialmente, con sus identidades etnorraciales-. Esos dos aspectos generaron el objetivo del estudio: entender cómo universitarios que ingresaron por políticas afirmativas estarian respondiendo $-\mathrm{y}$ cuestionando- a las politicas interculturales.

Esa inquietud nos llevó a construir una interpretación más cercana a la perspectiva de los principales actores de esas politicas -los y las estudiantes universitarios- desde la vertiente sociocultural de los estudios de literacidad (Heath, 1982; Street, 1993; Kleiman, 1995; Zavala, Niño-Murcia y Ames, 2004). Esa perspectiva, consolidada en Brasil desde 1990, centra su atención en los procesos interaccionales entre los sujetos, y busca comprender cómo las personas se apropian de la escritura.

Los estudios de literacidad irrumpieron en el panorama investigativo de los estudios antropológicos y etnográficos en la década de 1980, como una reacción contra una perspectiva evolucionista que, 
desde el siglo XIX, defendía la existencia de una gran fractura entre grupos letrados e iletrados (Ong, 1982). Esa visión estaba parcialmente fundamentada en experimentos en los cuales sujetos alfabetizados y no alfabetizados eran sometidos a pruebas de carácter cognitivo -resolver silogismos, hacer analogias, comparar, agrupar-, que demostraban que habia una diferencia significativa en las formas de resolver los problemas entre los dos grupos (Luria, 1976). Cuando las premisas de esos estudios comenzaron a ser cuestionadas (Scribner y Cole, 1981; Heath, 1982; Street, 1984), se comprobó que las diferencias relativas a la resolución de ese tipo de problema intelectual estaban correlacionadas con el grado de escolaridad, no con el analfabetismo, y que el conjunto de capacidades relacionadas con los usos de la lengua escrita dependía de factores sociales, como la interacción y las relaciones de poder, y su ejercicio entre los participantes de una situación comunicativa, fuese ella experimental o no. Por lo tanto, quedó comprobado que la literacidad, es decir, el dominio de diversos usos de la lengua escrita, así como el discurso y las representaciones sobre ella, son sociales. Y, como toda práctica social, las prácticas 'letradas' son heterogéneas, pluralistas, multiculturales (Barton y Hamilton, 2004). En ese nuevo y ampliado modelo sociocultural, "los estudios abandonaban la premisa de los efectos universales del letramento y presuponian efectos correlacionados a las prácticas sociales y culturales de los diversos grupos que usaban la escrita" (Kleiman, 1995, p. 16, traducción nuestra).

La perspectiva de los new literacy studies $^{8}$ se sustenta en una nueva teoría, más amplia, sobre los usos de la lengua escrita, que busca entender cómo las estructuras de poder orientan las prácticas sociales y, además, se contrapone a una concepción de la escritura como un instrumento, o una técnica, neutral. Una preocupación constante de las investigaciones se dirige a los escenarios escolares, académicos, burocráticos, en los cuales la escritura permanece como una herramienta que dificulta el derecho a la ciudadanía a grupos marginalizados (Rama, 1985; Freire, 1989; Kleiman, 2010).

8 Estudos do letramento, en portugués; new sudies of literacy, en inglés; y estudios de literacidad o cultura escrita, en español. 
En Brasil, los estudios de literacidad ocupan un lugar destacado en el área de la Lingüística aplicada, donde surgieron por las razones ya descritas, y también como un intento de separar los estudios sobre "el impacto social de la escritura" de los estudios sobre alfabetización, textualidad, habilidades cognitivas involucradas en la lectura y escritura, entre otros (Kleiman, 1995). En Colombia, esa perspectiva se viene posicionando más recientemente. Estudios como los de Soler (2013), Pérez y Rincón (2013) y Vargas Franco (2015) ilustran ese movimiento. Pérez y Rincón (2013), por ejemplo, parten de la pregunta “¿Para qué se lee y se escribe en la universidad colombiana?”, para reconocer el papel del lenguaje en la formación académica, utilizando metodologías cualitativas de investigación. Su propósito es contribuir a la construcción de una política para la formación académica que contemple el lenguaje. Así, el interés por comprender la perspectiva de los participantes acerca de sus usos del lenguaje y la mirada crítica constituyen una marca de esos trabajos.

En ese sentido, consideramos apropiada la propuesta de JouveMartín (2009), cuando afirma que, en Latinoamérica, construimos el campo de Estudios de Literacidad Latino-Americanos, pues los LALS (Latin American Literacy Studies) "forman parte de un movimiento intelectual más amplio que critica los modelos que han guiado el desarrollo intelectual, económico y político del continente" (p. 395). Esa visión crítica está anclada en una nueva comprensión del lenguaje, que contempla el vuelco cultural y lingüístico (Fabricio, 2006) que provocó cambios en la manera de concebir el lenguaje "como práctica social y [busca] observarla en uso, imbricada en una amplia amalgamación de factores contextuales" (p. 48, traducción nuestra).

En el grupo de investigación Letramento do Professor defendemos la investigación crítica de las prácticas letradas, basados en una concepción identitaria, lo que significa rechazar visiones instrumentales y funcionales del lenguaje, a fin de complejizar las relaciones humanas que son mediadas por este. Con el propósito de formar profesores, llamamos la atención sobre el hecho de que muchas veces el espacio educativo borra la historia social, tanto colectiva como individual. Por eso, un modo de romper con ese modelo es poner en el centro las 
narrativas de los sujetos, pues, conforme a lo que destaca Kleiman (2010), "el examen de esas trayectorias es relevante para entender el papel de la colectividad, de la resistencia, de la subversión en el proceso de literacidad de esos grupos" (p. 376, traducción nuestra). De esa forma, en nuestra labor investigativa hay una preocupación por "de-velar" las relaciones de poder que atraviesan el uso del lenguaje. Al examinar trayectorias que son construcciones colectivas de conocimiento, podemos percibir acciones de resistencias, subversiones y re-existencias en las formas de usar (o reinventar) la escritura (Valsechi, Sito, De Grande, Pereira y Vianna, 2014).

Transportando esa reflexión a la esfera académica, todavía hay una invisibilidad sobre el papel del lenguaje en la formación universitaria. Esa constatación es corroborada por Zavala y Córdova (2010, p. 113), quienes cuestionan que el discurso de la "crisis de la escritura” esté develando las bases de esa problemática en la educación superior, pues

en los últimos años, la investigación en este campo ha demostrado que las dificultades $y$, por consiguiente, los conflictos que emergen entre estudiantes y docentes con relación a la lectura y la escritura en la universidad no se restringen simplemente a la técnica de la lectura y la escritura, a las habilidades o a la gramática.

Detallando las concepciones de lenguaje en la esfera universitaria, Lea y Street (1998) propusieron tres modelos que sintetizarian las prácticas de uso de la lengua en esa esfera, de acuerdo a las nociones de lenguaje que los subyacen: el primer modelo, Study Skills, está basado en una concepción del lenguaje como habilidades, incorporando una visión del déficit hacia las prácticas de uso del lenguaje de los estudiantes; el segundo modelo, Academic Socialisation, propone que para aprender el discurso académico debe haber una socialización con el lenguaje de esa esfera, pero también comprende la escritura como un medio transparente de representación; y el tercer modelo, Academic Literacies, propone formar al estudiante para negociar las prácticas letradas dominantes. En ese modelo, la escritura es tomada 
como construcción de sentidos y contestación, y entran en escena las dimensiones de epistemología e identidad.

El enlace entre el estudio de Lea y Street (1998) y el contexto latinoamericano es realizado por Zavala y Córdova (2010), quienes investigaron las prácticas letradas de universitarios peruanos que habian ingresado a sus carreras por politicas afirmativas. Las autoras explican que el aprendizaje de la escritura académica produce tensiones en las trayectorias de literacidad de los universitarios. Sin embargo, esos conflictos no suelen resultar de un déficit individual -conforme sería entendido en el modelo de habilidades (Study Skills)-, sino que resultan de divergencias entre sus prácticas letradas escolares o familiares y las nuevas -las prácticas letradas académicas-. Al considerar ese aspecto, las autoras afirman que esas tensiones estarian más relacionadas con aspectos de identidad y poder. En otras palabras, eso significa que la apropiación del espacio universitario conlleva un aprendizaje de sus formas de lectura y escritura, y estas también estarian relacionadas con "nuestro sentido de pertenencia a la comunidad de la que intentamos formar parte, con las maneras de construir conocimiento y con las valoraciones diferenciadas que se adscriben a las diversas formas de lectura y escritura" (p. 113).

Esa forma de comprender el aprendizaje de las prácticas letradas académicas potencializa también las discusiones sobre los programas de acción afirmativa en la educación superior, en especial aquellos que tienen un perfil intercultural. Con esos programas, jóvenes que serán la primera generación de sus familias en ingresar a la universidad podrán participar en la comunidad universitaria. No obstante, el ingreso corresponde a apenas una parte de esa participación. Como señala Lillis (1999), al investigar las prácticas de escritura de jóvenes de familias sin tradición universitaria, existe una laguna entre las expectativas de los profesores y la comprensión de esos estudiantes-escritores acerca de las convenciones exigidas en la escritura académica. Así, la autora afirma que esas lagunas suelen ser analizadas de manera acrítica y comprendidas como una incompatibilidad que seria resuelta si los profesores explicaran más lo que exigen, lo que apunta a la visión de habilidades que subyace las formas de hacer en 
la esfera universitaria, que toma las convenciones como prácticas letradas desconectadas del contexto social (Lillis, 1999).

La noción de prácticas institucionales del misterio, de Lillis (1999), busca justamente explicitar esas dimensiones veladas que perjudican aun más a aquellos culturalmente distantes de la universidad, pues los modos de hacer y decir en cada contexto tienen sus convenciones, y en la universidad no es diferente. De ese modo, aquellos estudiantes que ingresan tienen que ir develando poco a poco esas convenciones, y ello, muchas veces, es atravesado por experiencias traumáticas.

El trabajo de Canagarajah (1997) describe cómo el uso de la escritura académica puede ser asociado a identidades raciales, cuando percibe que para sus estudiantes afroamericanos esa escritura representaba un "actuar como blanco" (acting white). Además, esa racialización de las prácticas letradas implicaba una resistencia por parte de los estudiantes a la apropiación de las convenciones de esa escritura. De manera similar, en el contexto peruano, Zavala (2009) también muestra conflictos que resultaban de la diferencia sobre concepciones del lenguaje entre estudiantes y sus docentes.

Esos estudios delinean la noción de literacidad académica, entendida como prácticas sociales de uso de escritura y lectura en la esfera académica. Pertinente en escenarios interculturales, este concepto nos permite analizar los choques en las zonas de contacto (Pratt, 1991), desde una perspectiva sociohistórica. En el contexto de las acciones afirmativas, señalamos que hay un proceso histórico de conflictos que se repiten hace años, los cuales acaban provocando, según Kleiman y Sito (en prensa, traducción nuestra) una

reescenificación del conflicto que hace siglos los grupos marginalizados sufren, primero en las manos del conquistador, y más tarde del colonizador (Collins y Blot, 2003), y hoy de la sociedad letrada en general: sus saberes eran ignorados, su habla ridiculizada en frente a colegas, su voz finalmente callada. 
Esa mirada culturalmente sensible propone un abordaje del lenguaje en la formación universitaria que reconozca las relaciones de poder, la identidad y la diversidad en las formas de construir conocimiento, adensada por la perspectiva decolonial (Castro-Gómez y Grosfoguel, 2007; Walsh, 2012), ya que esta intenta desestabilizar la geopolítica (asimétrica) del conocimiento.

Desde el punto de vista analítico, la noción de dialogismo nos permite examinar las narrativas de los estudiantes como una cadena de voces sociales que van reconstruyendo sus propias trayectorias, en diálogo con su contexto sincrónico y diacrónico. Con base en la teoría de lenguaje del círculo, de Bajtín, consideramos el discurso como una expresión de la interacción entre los sujetos y sus contextos sociohistóricos, pues "la enunciación es el producto de la interacción de dos individuos socialmente organizados" (Volóshinov, 1929/1995, p. 112, traducción nuestra). O sea, cuando nos enunciamos, nuestra palabra crea un lazo entre nosotros y nuestro interlocutor, a la vez que ubica nuestro tiempo y lugar históricos, a fin de expresar nuestro punto de vista o nuestra voz. La interacción, en la visión del círculo, es una expresión del diálogo infinito entre discursos que producimos como sociedad. Ningún discurso nace de la nada, sino como respuesta a otros ya dichos.

Así, enfocar las narrativas en sus historias personales lleva a identificar las formas a través de las cuales los estudiantes construyen discursivamente su recorrido en la universidad, así como el proceso por el cual tornaron ese espacio, que al inicio era tan raro e inhóspito, en un lugar familiar. Para entender otras formas de decir y percibir, analizamos el discurso de los estudiantes contando sus experiencias como una infinita cadena enunciativa, con base en la noción bajtiniana de dialogismo. $\mathrm{Y}$ es en ese ininterrumpido proceso dialógico que sus identidades académicas son, básicamente, construidas.

Desde el punto de vista metodológico, la investigación cualitativa tiene como objetivo producir comprensiones desarrolladas sobre bases de datos densos, contextualizados y detallados (Mason, 1996). Como en toda investigación cualitativa, se usaron métodos interactivos, 
objetivando el tratamiento de las personas como sujetos participantes de la construcción del conocimiento. Con ese fin, hubo negociación durante todo el proceso, para poder tener en cuenta las agendas de los propios sujetos.

La identificación de los estudiantes que podrian participar de la investigación fue resultado del diálogo con docentes y activistas sociales en cada una de las universidades. Gracias a su ayuda, entramos en contacto con 38 estudiantes que tenían el perfil adecuado para los objetivos del estudio: de ese total, realizamos una delimitación del público participante, focalizando la trayectoria de 8 universitarios -4 de Colombia y 4 de Brasil-, de cuyas entrevistas extraeremos los datos para el análisis que será presentado en la próxima sección.

En relación con la generación de los datos, utilizamos tres fuentes principales: entrevistas semiestructuradas con los estudiantes y sus orientadores y con gestores de los programas; tesis de conclusión de cursos de los estudiantes y documentos oficiales que: 1) regulaban las politicas de acción afirmativa de las universidades, o 2) orientaban la elaboración de las tesis de conclusión de cursos. Al adoptar una perspectiva cualitativa, nos apoyamos en la triangulación (Mason, 1996), es decir, utilizamos diversas fuentes para la recolección de datos. Los resultados del análisis que presentaremos, por lo tanto, provienen del entrecruzamiento de datos de las entrevistas de los estudiantes, con datos de entrevistas de gestores y orientadores, de análisis de diarios de campo, documentos oficiales de las instituciones de educación superior y de las tesis de conclusión de curso. Eso permite dar sentido a la "mezcla" de métodos requerida por la complejidad del objeto de investigación.

Las entrevistas semiestructuradas de los estudiantes abordaron experiencias en torno a la escritura y el proceso de elaboración de la tesis de conclusión de curso, sobre cuatro tópicos: 1) preingreso; 2) ingreso; 3) universidad, escritos y permanencia; y 4) tesis de conclusión de curso. Las entrevistas con los docentes, seleccionados porque sus estudiantes los consideraban buenos orientadores, nos permitieron conocer sus apreciaciones acerca de la experiencia de orientar la tesis 
de conclusión de curso. Todas esas entrevistas fueron grabadas en audio, y, posteriormente, segmentadas y transcritas.

Como ya hemos indicado, participaron en esta investigación estudiantes de dos universidades latinoamericanas, una colombiana y otra brasileña; instituciones públicas reconocidas por su calidad académica a nivel regional y nacional, que poseen programas de acción afirmativa hace más de cinco años: desde 2002, en Colombia, y desde 2008, en Brasil. Los estudiantes que participaron de la investigación eran de primera generación universitaria en sus familias, y el programa de acción afirmativa había sido un motivador adicional para su ingreso a la universidad.

Nuestro análisis lingüístico-discursivo se vuelca en este trabajo en las entrevistas de cuatro estudiantes: tres colombianas, Martina y Joyce -ambas de la licenciatura en Lenguas Extranjeras-y Elizabeth -de Trabajo Social-, y una brasileña, Flávia, de Ciencias Sociales.

\section{Trayectorias de literacidad: conflictos y re-existencias}

Conforme asumimos la palabra, con base en la concepción bajtiniana, esta es apenas una arena en la cual los acentos valorativos de los interlocutores están en un embate para marcar sus sentidos (Volóchinov, 1995). Así, el ejercicio de tornar la palabra ajena del otro en una palabra "mía" ocurre gradualmente, de modo que permite que la palabra en disputa se llene con "mis puntos de vista", respondiendo con "mis sentidos, valores y deseos" (el acento valorativo). Cuando el interlocutor responde y torna suya la palabra ajena, hay una apropiación de esa palabra, que designa el proceso de producción de conocimiento durante la actividad discursiva, que ocurre de forma continua, porque, desde la perspectiva dialógica del círculo de Bakhtin, la corriente discursiva es continua (Bakhtin, 1981/2004). Es el enunciado del sujeto lo que nos permite acceso a ese proceso de apropiación. 
Durante la entrevista, conversamos con las jóvenes sobre cómo ellas percibian las experiencias vividas en el recorrido de sus carreras. $\mathrm{Al}$ observar sus testimonios, nos topamos, por un lado, con narrativas de éxito, que registraban apenas los traumas, desplazamientos y pérdidas que tuvieron que enfrentar durante su ingreso a la universidad y, por otro, con las estrategias creadas para lograr su buen desempeño.

En los puntos que siguen, nos enfocaremos en dos dimensiones de esas trayectorias de (des)encuentros con la literacidad académica: una primera dimensión marcada por el extrañamiento frente a este "mundo nuevo" que representa la universidad, sea en sus modos de hacer, sea en sus convenciones para decir; y una segunda dimensión marcada por la creación de estrategias para lograr apropiarse de este nuevo espacio.

\section{La llegada al mundo nuevo: el extrañamiento}

Las estudiantes construyen narrativas en las que el momento de la llegada a la universidad es atravesado por una sensación de distancia, y marcado por conflictos debido al extrañamiento frente a los modos de hacer, decir y ser en la universidad. El relato de la estudiante Martina ${ }^{9}$, del programa de licenciatura en Lenguas Extranjeras, ilustra esa experiencia. Ella es de la comunidad Embera y vivia en otro departamento del país. Martina destaca que su deseo por cursar lenguas extranjeras surgió en la educación básica, en la escuela de su comunidad indígena, y que por eso se desplazó a Medellín para realizar su pregrado en una universidad pública colombiana. Narra, sin embargo, que sus primeros dias en el curso fueron marcados por el sufrimiento (entrevista efectuada el 6 de diciembre de 2013):

9 Los nombres de los participantes de la investigación son ficticios, para preservar sus identidades. 


\section{Extracto 1: "esto no es lo mío"10}

Entonces eso fue una experiencia un poco también traumática, porque la primera vez que llegué a la clase el profesor todo en inglés y yo no le entendia, no sabia nada. Pues, la profesora [del pueblo, que la había motivado a estudiar lenguas] era muy buena, pero después de ahí me di cuenta de que tampoco sabía mucho. (...) Yo llegué convencida de que yo sabía, pero cuando llegué allá me di cuenta de que no sabía nada. Entonces fue muy traumático porque yo, uff, yo no entendia nada y los compañeros venían de estudiar o afuera o en el Colombo, otros habían viajado, otros ya tenían su trayectoria estudiando inglés tres, cuatro años previos antes de entrar acá en la Universidad. Entonces yo ya era la única que estaba perdida totalmente. Y no le niego que yo ese día que sali, el primer dia, yo dije "esto no es lo mio".

Ese nuevo espacio-tiempo, en su narrativa, es descrito como una experiencia tensa ("fue una experiencia un poco también traumática") e incomprensible ("yo no le entendia, no sabía nada, no entendia nada, yo estaba perdida"). Esa experiencia tan negativa casi provocó la deserción de Martina: "Y no le niego que yo ese día que salí, el primer día, yo dije 'esto no es lo mío". Al revisitar su trayectoria en la universidad, Martina contrapone sus aspiraciones iniciales a ser docente de lenguas en su comunidad -lo mio-, con la incomprensión de las interacciones que se producian en la clase universitaria, que representa aquello que Volóshinov (1929/1995) describe como el discurso del otro, lo extranjero, lo ajeno, lo que no es suyo ("no le entendía"). Esa oposición proyecta una tensión entre la experiencia vivida en el espacio familiar, materializada en su comunidad, y aquella del otro desconocido e incomprendido; oposición que es expresada en la metáfora "esto no es lo mío", la cual señala justamente la sensación de falta de familiaridad e identificación con el nuevo espacio. Además, Martina se posiciona como ajena al grupo cuando describe que su sensación

\footnotetext{
10 Las convenciones de transcripción utilizadas para los extractos de entrevistas en este artículo son las siguientes: (/) quiebra abrupta del flujo del turno; (...) pausa de pequeña extensión; (...) suspensión de trecho de la transcripción original o parte incomprensible; (:::) alargamiento de la vocal; ("aaa") discurso relatado: ('comillas') lectura de texto.
} 
de estar fuera de lugar venía del hecho de sentirse la única "diferente" de aquel espacio ("yo ya era la única que estaba perdida totalmente").

Esa experiencia de choque también fue recurrente en las trayectorias de Brasil. La estudiante Flávia, afrobrasileña, del programa de Ciencias Sociales, también caracteriza esos primeros años en la universidad como un 'espacio' ajeno que le provocó sentimientos de "miedo" y "confusión".

\section{Extracto 2: "um mundo novo"}

Fue una confusión. Fue una confusión así en diferentes sentidos. Una confusión por estar en un mundo nuevo que se abre, que se presenta a mi alcance. Ah, un mundo nuevo que yo no compartía, entonces eso me dejó muy asustada, ¿entiende? Un mundo nuevo en el que estaba encontrando personas que no eran como yo, ah, en varios sentidos, en términos de cuestiones sociales, en términos de color y en términos de vivencias también, no eran personas que vivian en mi barrio ${ }^{11}$.

La estudiante ilustra su llegada con la metáfora del "mundo nuevo", que delinea sentimientos de distanciamiento, de estar fuera de un espacio del cual no hacía parte. El sentimiento de "confusión" es reiterado con énfasis por Flavia - esa palabra es repetida tres veces-y es atribuido a ese "mundo nuevo": la universidad. Además, ese sentimiento está relacionado con un gran movimiento de personas y ruidos, desorden, inquietud y embates. Así, la estudiante reconstruye un desplazamiento desde el antiguo espacio, marcado por el "barrio", al nuevo, "la universidad"; y su narrativa marca esa entrada en lo nuevo como una experiencia que le ha provocado miedo ("me deixou muito assustada"), extrañeza ("pessoas que não eram como eu", "não eram pessoas que viviam no meu bairro") y desubicación en relación con sus identidades de clase, color y lugar.

11 Original en portugués: "Foi um tumulto. Foi um tumulto assim em diferentes sentidos. Um tumulto por um mundo novo estar se abrindo, estar se apresentando assim ao meu alcance. Ah, um mundo novo que eu não compartilhava, então me deixou muito assustada, né? Um mundo novo por eu estar encontrando pessoas que não eram como eu, ah, em vários sentidos em termos de questões sociais, em termos de cor e em termos de vivências também, não eram pessoas que viviam no meu bairro". 
La distancia de la institución es descrita como un aspecto que provoca inquietud y embates, ya que este "mundo nuevo" parece generar una sensación de negación del mundo previo de la estudiante, pues es un espacio que ella no comparte, en el cual no encuentra personas similares ni de su comunidad de origen. Eso nos lleva a caracterizar las experiencias de ingreso como un momento de sus trayectorias marcado por el silencio y la negación de sí mismas; aspecto que cambia a lo largo del recorrido en el pregrado.

Martina y Flávia muestran cómo al alcanzar la educación superior, las diferencias entre su clase social ("questões sociais"), su identidad etnorracial ("cor") y sus trayectorias ("vivências", como viajes) y las de los demás colegas pueden ocasionar una deserción, debido a la hostilidad generada. Esos análisis corroboran estudios como los de Zavala (2009, 2011) y Canagarajah (1997), al explicitar cómo los marcadores sociales de diferencia atraviesan (y constituyen) los valores atribuidos a prácticas sociales, como las prácticas letradas académicas.

\section{La apropiación del mundo nuevo: creando estrategias para sobrevivir}

La segunda dimensión en la experiencia de literacidad académica registrada en las narrativas de las jóvenes revela cómo la inserción en la esfera universitaria les permite crear estrategias con las cuales aprenden a dominar las formas de comunicarse en el espacio académico y lograr éxito en sus trayectorias académicas. Para ello, se destacaron tres factores que las ayudaron a conquistar una participación más efectiva en la comunidad universitaria: el ingreso a grupos de investigación con temáticas étnicas, la constitución de redes sociales a lo largo de sus carreras y la presencia de mentores en su círculo más próximo. De esos factores, vamos a centrarnos en los dos primeros.

El relato de Joyce, estudiante colombiana de Licenciatura en Lenguas Extranjeras, del grupo indígena Nasa, describe su experiencia en un grupo de investigación que enfocaba temáticas indígenas (en entrevista realizada el 13 de diciembre de 2013). 


\section{Extracto 3: "volvi otra vez a revivir"}

Convocaron y fue ahi que yo me conoci con los estudiantes y ya y ahí digo que me sirvió mucho, y como que volví otra vez a revivir... me metí a trabajar allá con ella, pues a trabajar de monitora ayudándole con sus cosas, y ahí porque / yo empecé a meterme más en eso, y ahi me di cuenta de que existia la pedagogia de la madre tierra, me empecé a indagar por eso (...) percibir que existian más estudiantes indigenas entonces me metí por ahí. Conocí al profesor Abadio, ya conocí a otra gente, o sea, que yo ya empecé a entrar en otro mundo y eso me ayudó muchísimo.

En su narrativa, la participación en grupos de investigación sobre comunidades indígenas aparece como un aspecto relevante para que Joyce se reencuentre (“y como que volví otra vez a revivir"). La palabra "revivir" denota una nueva mirada suya frente a la universidad, como un espacio donde también podría comprender y hablar de lo "suyo" y "con los suyos" ("percibir que existian más estudiantes indígenas entonces me metí por ahî"). En un proceso contrario al del inicio del curso, cuando las estudiantes retrataban una anulación de sus culturas; ahora la estudiante se posiciona como alguien que pudo ampliar sus redes sociales y, a partir de ahí, reelaborar sus lazos con su comunidad de origen ("me di cuenta de que existía la pedagogía de la madre tierra, me empecé a indagar por eso") e incluso ampliar sus relaciones con otros grupos indígenas y ver la universidad de forma más cercana ("ya empecé a entrar en otro mundo").

La participación en un grupo de investigación que enfoca conocimientos que promueven identificación positiva de las estudiantes con sus grupos de origen motiva una conexión con la universidad, ya que no exige una ruptura con sus trayectorias previas. Además, les propicia una mejor comprensión sobre cómo funciona el espacio académico y una mejor apropiación de los códigos y convenciones de la institución.

El otro factor a resaltar fue la constitución de redes sociales. La universidad también fue retratada como un espacio de encuentros 
con otros de sus grupos, lo que algunas estudiantes trataron como un carácter cosmopolita de la institución. De esa forma, para estudiantes con identidades etnorraciales tan estigmatizadas, ingresar a la universidad fue una oportunidad para entrar más en contacto con otros estudiantes de su origen, como describe Elizabeth, estudiante afro-colombiana de Trabajo Social, en una entrevista efectuada el 20 de diciembre de 2013

\section{Extracto 4: "tuve muy pocos amigos afros"}

"Digamos que, por ejemplo, yo como nací acá en Medellín adquirí durante todo este tiempo la forma de ser de, o sea, la cultura de aquí de Medellín, sin embargo, y tuve muy pocos amigos afros, debido a que los espacios donde estaba todos eran mestizos, ¿cierto? Los amigos afros que encontré los encontré en la beca Martin Luther King y la universidad. Digamos que ellos sí venían de otras regiones del país.

Elizabeth caracteriza su contexto como un espacio "mestizo" ("tuve muy pocos amigos afros"), pero en su descripción podemos interpretar como un "mestizo" aquel que valora la blanquitud y niega los orígenes afros de la región, lo que resuena con la discusión de Wade (1997). Por eso, es justamente en la universidad -un espacio que entenderiamos como "blanco"- donde la estudiante se reencuentra con su negritud, pasa a autorreconocerse. Hay que destacar que las actividades promovidas por grupos del movimiento social y algunos proyectos orientados a la desconstrucción del racismo juegan un papel importante. En el caso de Elizabeth fue la participación en el Programa Martin Luther King, que reunía a jóvenes afrodescendientes e indígenas para cursos de inglés y formación en liderazgo, lo que fomentó un reencuentro positivo con su identidad racial.

Así, apuntamos cómo las estudiantes representan sus trayectorias de literacidad en dos grandes movimientos: primero, del familiar al desconocido, donde retratan sus primeros años, en los cuales la llegada a la universidad es representada como una ruptura entre un espacio familiar del "antes" - como la comunidad y el barrio-, visto 
como acogedor y feliz, y un espacio del "ahora" - la universidad- sentido como ajeno, asustador e inseguro. $\mathrm{Y}$ un segundo movimiento, del desconocido al familiar, donde retratan las estrategias desarrolladas durante la trayectoria del pregrado. El antes "mundo nuevo" es transformado en un espacio familiar u "otro mundo", evidente en la percepción de pertenencia de las estudiantes a la institución, según sus relatos. El ingreso a grupos de investigación con temáticas étnicas y la ampliación de contactos con colegas de la universidad con quienes se identificaban fueron las estrategias que focalizamos en ese proceso de apropiación de las prácticas de la universidad aquí descrito.

\section{Consideraciones finales: del "mundo nuevo" al "otro mundo"}

En este artículo buscamos mostrar algunos conflictos que emergieron durante la apropiación de prácticas de literacidad académica en las trayectorias de literacidad de universitarias afros e indígenas en un escenario de acciones afirmativas. Mostramos cómo esas estudiantes vivencian conflictos del proceso de apropiación de prácticas de literacidad académica, ya que necesitan lidiar con prácticas institucionales veladas, llenas de misterios, de la universidad. Aun así, crean estrategias para subvertir sentimientos de miedo y extrañeza (debido a la poca familiaridad) - "eso no es lo mio"- y pasar a sentirse parte de la universidad, a "revivir".

Al sumar un enfoque de la Lingüística aplicada en la discusión sobre políticas públicas y sistemas educativos en el sur global, como las acciones afirmativas, nos parece fundamental llamar la atención acerca de la relevancia de comprender más intimamente las experiencias de los sujetos que vivencian la implementación de esas politicas, así como escuchar sus propuestas alternativas a nuestras instituciones, que persisten en su estructura excluyente, aun en el escenario actual de interculturalidad. Los conflictos de los estudiantes en sus trayectorias de literacidad académica, además de denotar (des) encuentros con la universidad, son índices que interpelan las políticas 
interculturales desde sus experiencias, revelando aspectos de la vida universitaria que no suelen ser contemplados en las discusiones de permanencia de los programas de acción afirmativa, como la interculturalidad y el lenguaje.

\section{Referencias}

Arruti, J. M. A. (2000, novembro). Direitos étnicos no Brasil e na Colômbia: notas comparativas sobre hibridação, segmentação e mobilização política de indios e negros. Horizontes Antropológicos, 6(14), 93-123.

Bakhtin, M. (1981/2004). The dialogic imagination (M. Holquist, Org. y Trad.). Austin: University of Texas Press.

Barton, D. y Hamilton, M. (2004). La literacidad entendida como práctica social. En V. Zavala, M. Niño-Murcia y P. Ames (Eds.), Escritura y sociedad: nuevas perspectivas teóricas y etnográficas (pp. 109-139). Lima: Red para el Desarrollo de las Ciencias Sociales en el Perú.

Canagarajah, A. S. (1997, may). Safe houses in the contact zone: coping strategies of african-american students in the academy. College Composition and Communication, 48(2), 173-196.

Carvalho, J. J. (2004). Inclusão Étnica e Racial no Brasil. A questão das cotas no ensino superior. São Paulo: Attar Editorial.

Castro-Gómez, S. y Grosfoguel, R. (Eds.). (2007). El giro decolonial: reflexiones para una diversidad epistémica más allá del capitalismo global. Bogotá: Siglo del Hombre Editores - Instituto de Estudios Sociales Contemporáneos, Universidad Central - Instituto Pensar.

Fabrício, B. F. (2006). Linguística Aplicada como espaço de desaprendizagem: redescrições em curso. En L. P. Moita Lopes (Org.), Por uma linguística indisciplinar (pp. 233-252). São Paulo: Parábola. 
Freire, A. M. A. (1989). Analfabetismo no Brasil: da ideologia da interdição do corpo à ideologia nacionalista, ou de como deixar sem ler e escrever desde Catarinas (Paraguaçu), Filipas, Madalenas, Anãs, Genebras, Apolônias e Gracias até os Severinos. São Paulo - Brasília, DF: Cortez - INEP.

Goffman, E. (1988). Estigma: notas sobre a manipulação da identidade deteriorada (4. Ed.) [M. Lambert, Trad.]. Rio de Janeiro: Livros técnicos e científicos.

Heath, S. B. (1982). What no bedtime story means: narrative skills at home and school. Language and Society, 11, 49-76.

Jouve-Martín, J. R. (2009). Escritura, hegemonia y subalternidade: de los New Literacy Studies (NLS) a los Latin American Literacy Studies (LALS), and back. En J. Kalman y B. Street (Coords.), Lectura, escritura y matemáticas como prácticas sociales: diálogos con América Latina (pp.387-398). México: Siglo XXI - CREFAL.

Kleiman, A. B. (1995). Modelos de letramento e as práticas de alfabetização na escola. En A. B. Kleiman (Org.), Os significados do letramento: uma nova perspectiva sobre a prática social da escrita (pp. 15-61). Campinas, SP: Mercado Aberto.

Kleiman, A. B. (2010, jul.-dez.). Trajetórias de acesso ao mundo da escrita: relevância das práticas não escolares de letramento para o letramento escolar. Perspectiva, 28(2), 375-400.

Kleiman, A. B. e Sito, L. (En prensa). Multiletramentos, interdições e marginalidades. Em A. B. Kleiman y J. Assis (Orgs.), Significados e ressignificações do letramento. Desdobramentos de uma perspectiva sociocultural sobre a escrita (pp. 169-198). Campinas, SP: Mercado de Letras.

Lea, M. R. and Street, B. (1998, june). Student writing in higher education: an academic literacies approach. Studies in Higher Education, 23(2), 157-173.

Lillis, T. (1999). Whose "Common Sense"? Essayist literacy and the institutional practice of mystery. En C. Jones, J. Turner and B. Street (Orgs.), Students 
writing in the university: cultural and epistemological issues. Amsterdã, USA: John Benjamins Publishing.

Luria, A. L. (1976). Cognitive Development. Its cultural and social foundations. Cambridge: Harvard University Press.

Mason, J. (1996). Qualitative researching. London: SAGE Publications.

Moreira, M. S. e Pereira, L. (2011, agosto). Confrontando argumentos: raça, estado e democracia no debate acadêmico sobre as cotas no Brasil. En XI Congresso Luso-Afro-Brasileiro de Ciências Sociais - CONLAB. Diversidades e (Des)Igualdades, Universidade Federal da Bahia (UFBA), Salvador.

Munanga, K. (1999). Rediscutindo a mestiçagem no Brasil. Identidade nacional versus identidade negra. Rio de Janeiro: Ed. Vozes.

Oliven, R. G. (1999). Nación y modernidad. La invención de la identidad gaucha en el Brasil (O. Agüero, Trad.). Buenos Aires: Eudeba.

Ong, W. J. (1982). Orality and Literacy. The technologizing of the word. Londres: Meuthen.

ONU. (2001). Declaração e Programa de Ação da III Conferência Mundial contra o Racismo, Discriminação Racial, Xenofobia e Intolerância Correlata. Durban, 31 de agosto a 08 de setembro 1. Recuperado de http://www.unifem.org.br/ sites/700/710/00001626.pdf

Pérez, M. y Rincón, G. (2013). ¿Para qué se lee y se escribe en la universidad colombiana? Un aporte a la consolidación de la cultura académica del país. Bogotá: Editorial Pontificia Universidad Javeriana.

Pratt, M. L. (1991). Arts of the Contact Zone. Profession, 91, 33-40.

Quijano, A. (2005). Colonialidad del poder, eurocentrismo y América Latina. En E. Lander (Ed.), La colonialidad del saber: eurocentrismo y ciencias sociales. Perspectivas latinoamericanas (pp. 201-246). Buenos Aires: Colección Sur Sur, CLACSO - Ciudad Autónoma de Argentina. 
Rama, A. (1985). A cidade das letras. São Paulo: Editora Brasiliense S.A.

Rodrigues, V. (2012). Entre quilombos e palenques: um estudo antropológico sobre politicas públicas de reconhecimento no Brasil e na Colômbia (Tese Doutorado em Antropologia Social). Faculdade de Filosofia, Letras e Ciências Humanas, Universidade de São Paulo, São Paulo.

Scribner, S. and Cole, M. (1981). The Psychology of Literacy. Cambridge: Harvard University Press.

Sierra, Z. (Ed.). (2004). Voces indigenas universitarias. Expectativas, vivencias y sueños (1. Ed.). Medellín: Colciencias - Grupo Diverser, Universidad de Antioquia - IESALC -UNESCO - OIA - INDEI.

Sito, L. (2014, ene-jun). Disputas e diálogos em torno do conceito de "ações afirmativas" para o ensino superior no Brasil. Universitas Humanística, 77, 251-273.

Sito, L. (2016). Escritas afirmativas: estratégias criativas para subverter a colonialidade em trajetórias de letramento acadêmico. (Tese Doutorado em Linguística Aplicada), Instituto de Estudos da Linguagem, Universidade Estadual de Campinas, Campinas.

Soler, S. (2013). Usted ya en la universidad y no saber escribir. Escritura y poder en la universidad. Bogotá: Universidad Distrital Francisco José de Caldas.

Street, B. V. (1984). Literacy in Theory and Practice. Cambridge: Cambridge University Press.

Street, B. V. (Org.). (1993). Cross-cultural approaches to literacy. Cambridge: Cambridge University Press.

Valsechi, M., Sito, L., De Grande, P., Pereira, S. y Vianna, C. (2014, agosto). Legitimação dos participantes e rompimento de assimetrias: contribuições do grupo Letramento do professor para o campo dos estudos de letramento. En Anais do V Colóquio Internacional Letramento e Cultura Escrita, Belo Horizonte. 
Vargas Franco, A. (2015, julio-diciembre). Literacidad critica y literacidades digitales: ¿una relación necesaria? Una aproximación a un marco teórico para la lectura crítica. Revista Folios, 42, 139-160.

Viveros, M. (2013, enero-junio). Género, raza y nación. Los réditos politicos de la masculinidad blanca en Colombia. Maguaré, 27(1), 71-104.

Volóshinov, V. N. (1929/1995). Marxismo e Filosofia da Linguagem (Ed. 7) [M. Lahud y Y. Frateschi Vieira, Trads.]. São Paulo: Hucitec.

Wade, P. (1997). Gente negra. Nación mestiza: dinámicas de las identidades raciales en Colombia. Bogotá: Siglo del Hombre Editores.

Walsh, C. (2012). Interculturalidad y (de)colonialidad: perspectivas críticas y políticas. Visão Global, 15(1-2), 61-74.

Zavala, V. (2009). “¿Quién está diciendo eso?”: literacidad académica, identidad y poder en la educación superior. En J. Kalman y B. Street (Coords.), Lectura, escritura y matemáticas como prácticas sociales: diálogos con América Latina (pp. 348-363). México: Siglo XXI - CREFAL.

Zavala, V. (2011). La escritura académica y la agencia de los sujetos. Cuaderno comillas, 1, 52-66.

Zavala, V. y Córdova, G. (Orgs.). (2010). Decir y callar. Lenguaje, equidad y poder en la universidad peruana. Lima: Editorial de la Pontificia Universidad Católica del Perú.

Zavala, V., Niño-Murcia, M. y Ames, P. (Eds.). (2004). Escritura y sociedad. Nuevas perspectivas teóricas y etnográficas. Lima: Red para el Desarrollo de las Ciencias Sociales en el Perú.

\section{Cómo citar este artículo}

Sito, L. y Kleiman, A. (2017). "Eso no es lo mío": un análisis de conflictos en la apropiación de prácticas de literacidad académica. Universitas Humanística, 83, 159-185. http://dx.doi.org/10.11144/Javeriana.uh83.acap 